\title{
Fields in Human Motor Areas Involved in Preparation for Reaching, Actual Reaching, and Visuomotor Learning: A Positron Emission Tomography Study
}

\author{
Ryuta Kawashima, ${ }^{a}$ Per E. Roland, and Brendan T. O'Sullivan \\ Division of Human Brain Research, Department of Neuroscience, Karolinska Institute, S171 77, Stockholm, Sweden
}

The purpose of this study was to examine the functional organization of motor cortices in the human brain involved in reaching and visuomotor learning. All subjects were asked to learn the positions of seven circular targets projected on a screen. Each time the targets were turned off, they were required to close their eyes and keep them closed, and, after a delay, to point to the center of the targets in a prescribed order using their right hand. The regional cerebral blood flow (rCBF) was measured with ${ }^{15} \mathrm{O}$-butanol and positron emission tomography in $\mathbf{2 0}$ subjects during a rest state, an initial learning stage, and a later learning stage. Ten subjects constituted the reaching group in which rCBF was measured during actual reaching; the 10 other subjects constituted the preparation group in which rCBF was measured in the delay period between target exposure and actual reaching. Individual subtraction images (each stage minus rest) were calculated and transformed into a standard size and shape brain image by the adjustable computerized brain atlas and averaged, after which significant changes of rCBF were identified. In all reaching and preparation for reaching phases, cortical fields were activated in the left primary motor area (M1) and the left premotor area (PMA). Within M1, fields active in the delay phases were adjacent to the fields active only during actual reaching movements. During the course of learning, additional fields of activity appeared in both M1 and PMA. The results indicate that three types of fields occur in M1 and PMA: (1) fields directly engaged in the efferent control of peripheral muscle contraction, (2) fields engaged in preparatory activity for reaching, and (3) fields appearing after learning of the task has taken place.

IKey words: human, primary motor area, premotor cortex, positron emission tomography, movement preparation, motor learning]

\footnotetext{
Received Mar. 10, 1993; revised Sept. 9, 1993; accepted Nov. 24, 1993

This study was supported by grants from the Human Frontier Science Programme Organization, The Swedish Medical Research Council, a travel grant to R.K. from The Scandinavian Japanese Radiological Society, and a Research Fellowship to B.T.O. from the N.S.W. Institute of Psychiatry, Australia. We thank Walter Pulka for radiochemical synthesis.

Correspondence should be addressed to Prof. Per E. Roland, Division of Human Brain Research, Department of Neuroscience, Karolinska Institute, S171 77, Stockholm, Sweden.

a Present address: Department of Nuclear Medicine and Radiology, Institute of Development, Aging and Cancer, Tohoku University, 4-1 Seiryocho, Sendai 980, Japan.

b Present address: Department of Nuclear Medicine, Royal Prince Alfred Hospital, Camperdown, NSW2050, Australia.

Copyright (C) 1994 Society for Neuroscience $0270-6474 / 94 / 143462-13 \$ 05.00 / 0$
}

The primary motor area (Ml) of the cerebral cortex is generally considered to be involved only in the execution of peripheral muscle contraction. Recently, however, this conventional view of the physiological role of M1 has been challenged. Studies examining the patterns of neuronal activity in $\mathrm{Ml}$ in monkeys suggest a further role for this area in higher-order motor control, such as in the processing of visuomotor information and in the preparation for motor execution (Godschalk et al., 1981; Georgopoulos et al., 1986, 1989; Schwartz et al., 1988; Kalaska et al., 1989; Alexander and Crutcher, 1990a,b; Caminiti et al., 1990; Kalaska and Crammond, 1992). Electrical microstimulation studies of the monkey M1 have demonstrated representation of different body parts (Sato and Tanji, 1989; Schmidt and McIntosh, 1990) as well as "silent zones" where no muscle contractions are generated (Waters et al., 1990). Alexander and Crutcher (1990a) reported two populations of neurons, one being movement related and the other active in preparation for movements. These two populations tended to be located in separate regions in $\mathrm{M} 1$, thus providing further evidence of functional heterogeneity within Ml.

In contrast to monkey studies, no studies have yet demonstrated that the human Ml is involved in the preparation and planning of movements. Electroencephalographic and magnetoencephalographic studies have demonstrated changes in activity through the scalp over the region of sensorimotor area and over the supplementary motor area (SMA) while subjects were preparing for movement (Deecke, 1987; Chiarenza et al., 1990; Niemann et al., 1991; Lang et al., 1992). However, these methods have limited spatial resolution, so specific sites of activation could not be identified precisely.

A tight coupling of changes in neuronal activity to regional cerebral blood flow ( $\mathrm{rCBF}$ ) changes has been demonstrated previously (Raichle et al., 1976; Kuschinsky and Wahl, 1978; Sokoloff, 1981). Studies in which the rCBF has been used to map the activity of neurons and synapses have therefore been used to study the organization of motor control in man. Two studies in which the ${ }^{133} \mathrm{Xe}$ intracarotid injection method was used to determine rCBF did not show significant increases in $\mathrm{rCBF}$ in the human M1 during the planning of a sequence of ballistic movements, that is, before the actual execution of the movements (Roland et al., 1980a; Gelmers, 1981). However, precise anatomical localization was difficult in these studies.

Positron emission tomography (PET) techniques for mapping the functional organization of the human brain have now achieved sufficient spatial resolution to identify specific sites of activation in the human cortex (Fox et al., 1988; Roland et al., 1993). To date, PET researchers have reported rCBF changes 
in M1 in relation to a variety of movement parameters and tasks, such as selection of movement (Deiber et al., 1991) and laterality of movement (Kawashima et al., 1993). Another study has demonstrated a somatotopic representation within M1 although no attempt was made to test the continuity of the somatotopical representation of movement related $\mathrm{rCBF}$ changes (Grafton et al., 1991). Seitz and Roland (1992) and Grafton et al. (1992) have shown rCBF changes that occur in motor skill learning, however, with the exception of a preliminary report (Fox et al., 1987), none of these previous PET studies has specifically attempted to relate $\mathrm{rCBF}$ changes to the different phases of motor control, namely, motor preparation and execution of movements.

The present study was designed to examine whether there are two different maps in M1, PMA, and SMA, one consisting of neurons related to preparatory activity, and the other consisting of neurons related to execution of movements. To do this, we used a high-resolution PET camera to identify specific cortical fields in human motor areas, which were activated during the course of learning a visuomotor reaching task. Two groups of normal adults were studied to compare the distribution of fields of activation during the delay period between target exposure and reaching, and during the reaching period itself. The computerized brain atlas (CBA) (Bohm et al., 1986) was used in order to provide precise anatomical location of activated fields on population mean PET images.

Some preliminary data from a part of this study have been reported previously (Decety et al., 1992).

\section{Materials and Methods}

\section{Subjects and task procedure}

Twenty healthy right-handed male volunteers (aged 20-36 years) participated in the study. The subjects were divided into two groups (preparation group and reaching group) with 10 in each group. There was no significant difference in mean ages between the two groups. Handedness was assessed by the Edinburgh questionnaire (Oldfield, 1971). The mean $( \pm$ SD) laterality quotient of the preparation group and the reaching group was $81.3 \pm 14.7$ and $80.0 \pm 18.0$, respectively. Written informed consent was obtained according to the requirements of the Ethics Committee and the Radiation Safety Committee of the Karolinska Institute and the Declaration of Human Rights, Helsinki 1975. Prior to the PET experiment, each subject had a catheter placed into the right brachial vein for tracer administration and another inserted, under local anesthesia, into the left brachial artery for the measurement of arterial tracer concentration and $\mathrm{PaCO}_{2}$. Each subject wore a stereotaxic fixation helmet (Bergström et al., 1981) during the PET measurements. A highresolution magnetic resonance imaging (MRI) scan was also performed with the subjects using this same stereotaxic helmet on a separate occasion. The subjects lay in a supine position on the bed of the PET scanner. They were not allowed to speak during the procedure and had been instructed not to think of anything in particular, except concentrate on the task. The room was kept as quiet as possible.

Both preparation and reaching groups performed the same delayed reaching task (Fig. 1a). On each trial, subjects were instructed to "LOOK" at the positions of seven circular targets of different sizes that were projected for $5 \mathrm{sec}$ on a screen in front of them and to memorize their positions in increasing order of size. The targets consisted of group of seven circular white spots on a blue background projected on a screen $(75 \mathrm{~cm}$ width $\times 52 \mathrm{~cm}$ height) at a distance of $60 \mathrm{~cm}$ from the subjects' eyes. The spots were randomly arranged as shown in Figure $1 b$, with diameters ranging from $15 \mathrm{~mm}$ to $95 \mathrm{~mm}$. After the cue period, subjects closed their eyes and waited for a further command to "POINT." When this command was given, they were required, still with their eyes closed, to touch the centers of these targets in the correct order of increasing target size with the right index finger as accurately as possible. Thus, each "POINT" command was followed by seven reaching movements to the seven targets. After a variable intertrial interval, the start signal to "LOOK" was again given and the learning trial procedure was re-
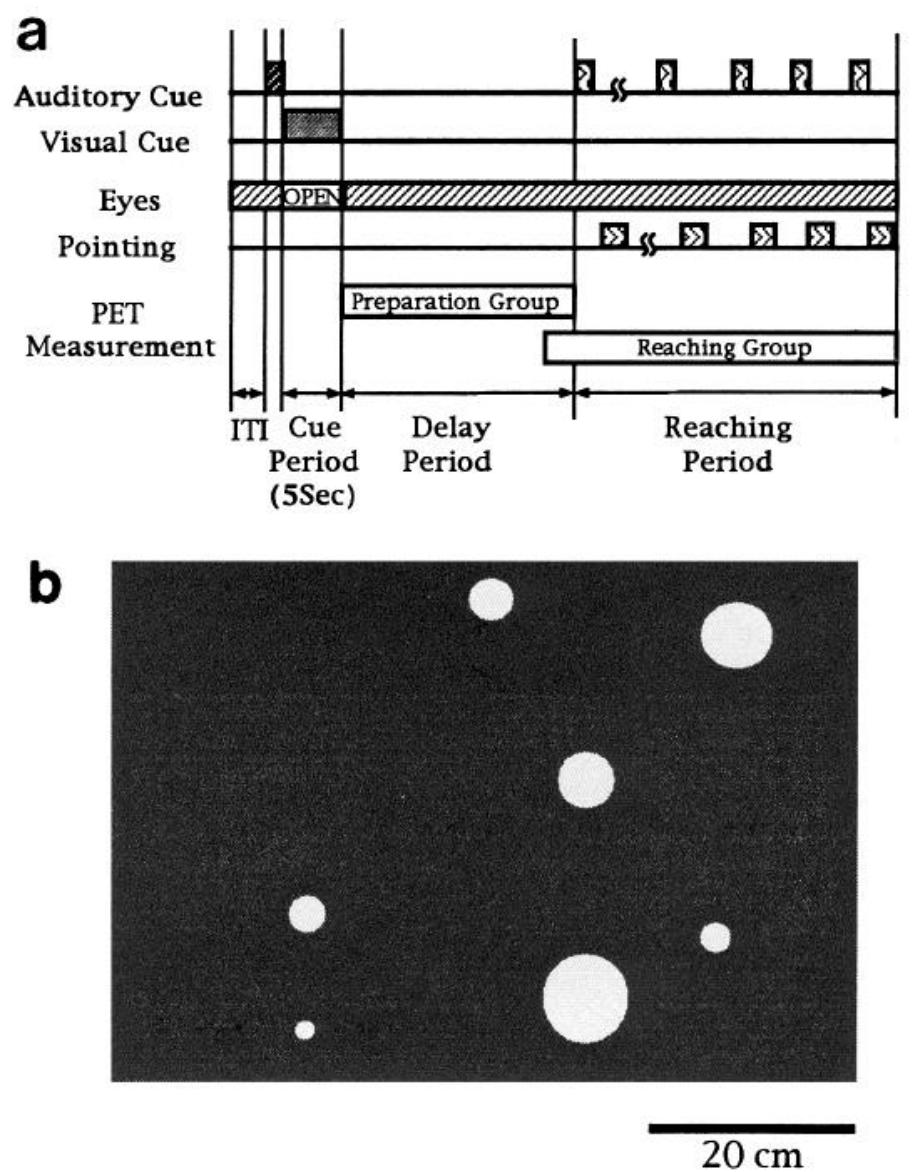

Figure 1. Schematic diagram of the reaching task (a). On each trial, subjects were instructed to "LOOK" (Auditory Cue) at the positions of seven circular targets of different sizes, which were projected for $5 \mathrm{sec}$ on a screen in front of them, and to memorize their positions in increasing order of size (Cue Period). The targets are shown in $b$. The subjects then closed their eyes and waited for (Delay Period) a further command to "POINT" (Auditory Cue). When this command was given, they were required, still with their eyes closed, to touch the centers of the targets in the correct order with the right index finger (Reaching Period). After a variable intertrial interval $(I T I)$, the start signal to "LOOK" was again given and the learning trial procedure was repeated in the same fashion. The Preparation Group subjects pointed at the pattern of targets only one time for each learning trial. The Reaching Group subjects pointed at the pattern of targets a total of 13 times during the PET run, although usually only one to five times for all other learning trials. The CBF measurements were done during an initial phase of learning at the 3 rd trial, and during a final phase of learning, at the 25 th trial. In the Preparation Group subjects, PET measurements started immediately after the Cue Period was over, and continued for $90 \mathrm{sec}$ during the Delay Period. In the Reaching Group subjects, the CBF measurements commenced $20 \mathrm{sec}$ before the "POINT" command, and continued for a period of $170 \mathrm{sec}$ during the Reaching Period.

peated in the same fashion. The target exposure was repeated for a total of 25 times for each group, and rCBF measurements were obtained during an initial phase of learning at the 3rd trial, and during a final phase of learning, at the 25 th trial. The subjects did not get any feedback of their performance or any knowledge of their result.

In the preparation group, the radioisotope was injected and the $\mathrm{rCBF}$ measurements commenced immediately after the visual cue period was over and the targets were turned off (Fig. 1a). The PET scanning then continued for $90 \mathrm{sec}$ during this delay period and finished immediately before the "POINT" command was given. That is, there was no actual reaching movement during either of the two PET scans of the delay phase at $3 \mathrm{rd}$ and 25 th learning trials. Subjects pointed at the pattern of targets only one time for each learning trial. 


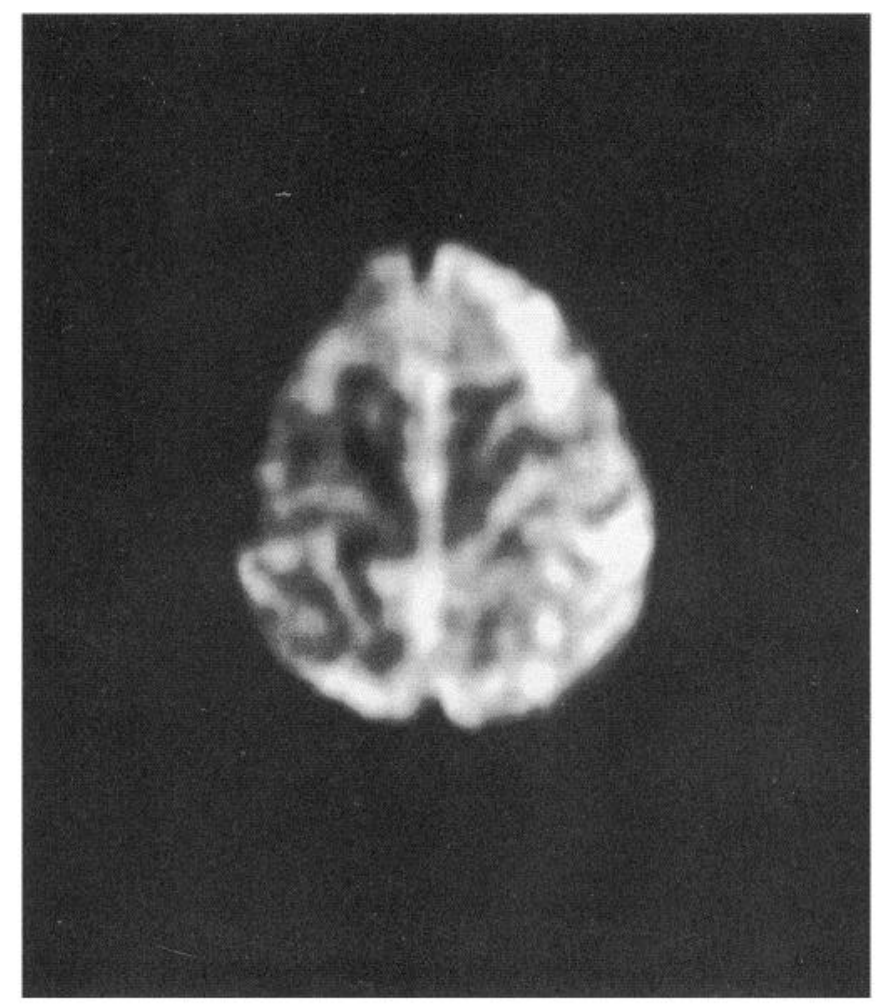

Figure 2. The mean reformatted MRI. Each subject's MRI (T2-weighted images) was transformed into the standard atlas brain anatomy by both linear and nonlinear parameters using the computerized brain atlas (CBA) of Bohm et al. (1986). These parameters were subsequently used to transform the PET images. In order to obtain precise anatomical information about motor areas in the transformed PET images, the course of the sulci was identified from this average reformatted MRI of the 20 subjects involved in this study. The contour of the brain surface, and location of the bilateral central, precentral, postcentral, and superior frontal sulci are clearly identifiable in this image.

In the reaching group, the radioisotope was injected after the delay phase, and when the injection was completed the subjects received the "POINT" command. PET scanning commenced $20 \mathrm{sec}$ before the "POINT" command and continued for a period of $180 \mathrm{sec}$ while the subjects recalled and pointed to the targets several times in the same order. Two PET scans of the actual reaching phase at the 3rd and the 25 th learning trials were performed. The subjects of the reaching group received 13 "POINT" commands during the $180 \mathrm{sec}$ of PET measurement. They thus pointed at all seven targets a total of 13 times during the $180 \mathrm{sec}$ of each PET run. The commands to "POINT" were given with variable delays. In the learning trials on the contrary, the subjects of the reaching group received from one to five "POINT" commands and pointed from one to five times of all seven targets following each exposure of the targets. The number of "POINT" commands given for each learning trial (from one to five) was random to minimize anticipation.

For both preparation and reaching groups, a PET scan of a rest state was also obtained. The rest state used has been previously defined by Roland and Larsen (1976), in which subjects have their eyes closed and are instructed to lie quietly, without moving. The order of the rest state was randomized as either the first or the last measurement.

Behavioral analysis. In the reaching group, a video recording was made throughout the entire study for an analysis of each subject's reaching performance. In the preparation group, a similar video recording was made, but was unfortunately of such poor quality that this precluded accurate measurements. In order to get a learning curve of subjects pointing only once after each exposure of the target, video recordings were also made of an additional five right-handed, age-matched male subjects for a total of 50 learning trials. In these subjects, exactly the same procedure was used as for preparation group, except that the stereotaxic helmet and catheters were not used and no PET measurement was taken. An electroencephalogram (EEG), electrooculogram (EOG), and forearm electromyogram (EMG) with superficial electrodes were recorded in the preparation group. In the reaching group, EEG and EOG recordings were made throughout the PET measurements.

PET measurement. All rCBF measurements were performed with an eight ring (15 slice) PET camera (PC2048-15B Scanditronix) that has in-plane spatial resolution of full width at half-maximum of $4.5 \mathrm{~mm}$ and an interslice distance of $6.5 \mathrm{~mm}$ (Litton et al., 1990). ${ }^{15} \mathrm{O}$-butanol was synthetized by the method of Berridge et al. (1991). A bolus injection of $70 \mathrm{mCi}$ of ${ }^{15} \mathrm{O}$-butanol was used in each PET run. Absolute values of $\mathrm{rCBF}$ were then calculated on the basis of data collected between 0 and $80 \mathrm{sec}$ from the start of the injection. Details of this calculation have been described previously (Roland et al., 1987, 1993). The rCBF was calculated voxel by voxel by the dynamic approach using the algorithm of Koeppe et al. (1985). For this calculation, we used a bloodbrain partition coefficient of 0.78 for butanol in gray matter (Roland et al., 1993). Since the values of global CBF change by $4 \%$ per $\mathrm{mm}$ change in $\mathrm{PaCO}_{2}$ as described by Olsen et al. (1971), the differences in global $\mathrm{CBF}$ due to differences in $\mathrm{PaCO}_{2}$ between measurements in each subject were corrected to that of rest condition for test minus rest comparisons and similar correction for test minus test comparisons (Roland et al., 1987). Pictures of rCBF changes were calculated as voxel-by-voxel subtractions of the rest image from each test image and also of test minus test images.

Anatomical standardization. As previously described (Seitz et al., 1990), the anatomical structures of the computerized brain atlas (CBA) of Bohm et al. (1986) were fitted interactively to each subject's MRI. Each individual MRI was transformed to the size and shape of the standard brain of the atlas, by both linear and nonlinear parameters. These parameters were subsequently used to transform the subtraction PET images into the standard atlas brain anatomy. In order to obtain precise anatomical information about the precentral region from the transformed PET images, considerable care was taken in fitting the brain atlas to the position of the left central sulcus, the precentral sulcus, the superior frontal sulcus, and the surface of the brain in each individual MRI. However, in this series of subjects, we found the deeper part of the precentral sulcus and superior frontal sulcus to deviate slightly from the course of the corresponding atlas sulci. Therefore, the deeper part of the sulci was identified from the average $\mathrm{T} 2$-weighted anatomically standardized MRI of the 20 subjects in this study (Fig. 2). In the subsequent figures (see Figs. 8-11) and in the analysis of the data, the mean geometrical course of the central, precentral, and superior frontal sulcus was determined from the average T2-weighted reformatted MRI as the points with the largest signal intensity. In addition, deviation of each subject's sulcus from the population mean course was calculated.

Our PET system has a sufficient spatial resolution $(4.5 \mathrm{~mm})$ to differentiate activated fields within M1 and PMA in individual brain images, although it is not possible, of course, to differentiate separate cortical layers in an activated field. Second, our CBA system allows us to differentiate activated fields in population mean images with a resolution below that of the resolution of the PET camera (Fox et al., 1988). As previously reported (Seitz et al., 1990), the precision of the reformatation process has an SD of $2-3 \mathrm{~mm}$ in the localization of the inner and outer brain surfaces. In this series of subjects, we found the deeper part of the precentral sulcus and superior frontal sulcus to be slightly different from the course of the corresponding atlas sulci. Therefore, the mean geometrical course of the deep part of the sulci was obtained from the average reformatted MRI of the same 20 subjects participating in this study (Fig. 2). Figure 3 shows the course of the central, precentral, and superior frontal sulci in each subject's anatomically standardized MRI and also the mean course of these sulci in the mean picture of the anatomically standardized MRIs. The standard error of mean (SEM) of the course was as follows: central sulcus, $0.47 \mathrm{~mm}$; precentral sulcus, $0.49 \mathrm{~mm}$; and superior frontal sulcus, $0.60 \mathrm{~mm}$. This is much less than the spatial resolution of our PET camera and the size of the fields of activation. Therefore, we feel that the reformatation procedure is sufficiently accurate to localize the functional fields correctly with respect to the anterior, posterior, medial, or lateral banks of the three sulci.

A tight coupling of normal synaptic activity with $\mathrm{rCBF}$ has been well demonstrated in response to specific tasks, with the location of changes in $\mathrm{rCBF}$ matching with the functional field's synaptic metabolic activity (Raichle et al., 1976; Kuschinsky and Wahl, 1978; Sokoloff, 1981). This is the basis for all current PET activation techniques. The measurement of $\mathrm{rCBF}$ changes with PET is therefore considered to be an indirect but 


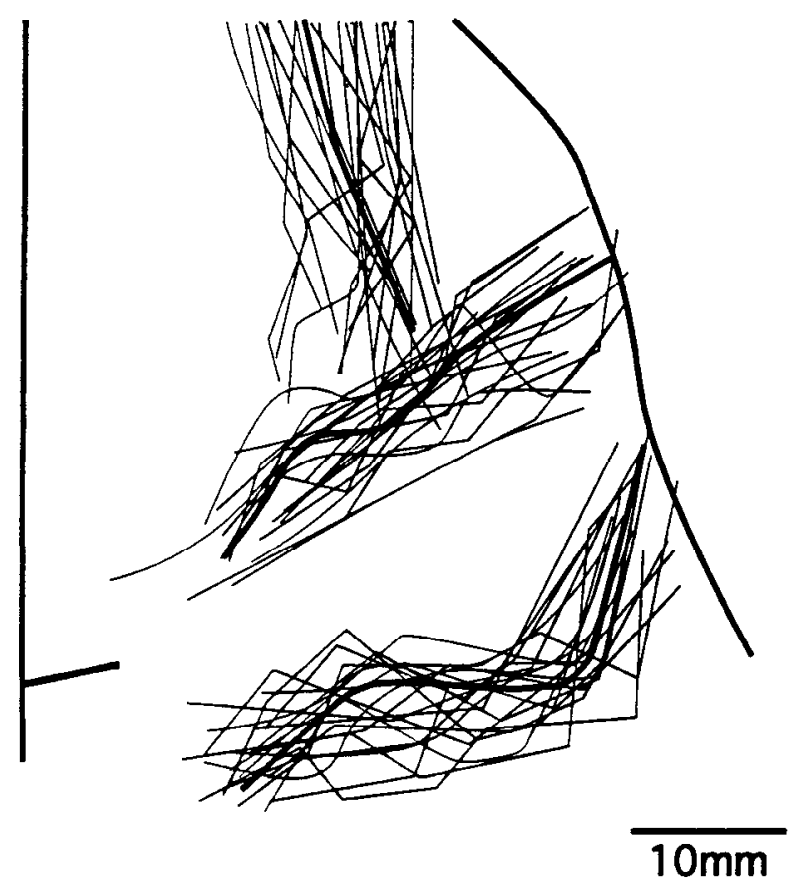

Figure 3. Section of the brain showing the topographic distribution of the course of the central, precentral, and superior frontal sulci. The format is the same as in Figure 8. Thick lines indicate the mean geometric course of the deep part of the sulci that was determined from the average T2-weighted reformatted MRI as the points with the largest signal intensily. Thin lines indicate the course of the sulci that were oblained from each individual reformatted MRI. The SEMs of the course of the principal sulci were as follows: central sulcus, $0.47 \mathrm{~mm}$; precentral sulcus, $0.49 \mathrm{~mm}$; and superior frontal sulcus $0.60 \mathrm{~mm}$.

quantitative measure of synaptic metabolic activity. It is presumed that fields showing high synaptic activity have a large probability that the neurons contained in the field also fire.

The delimitation of activated fields in this study was based on the statistical analysis of the cluster detection (Roland et al., 1993). Figure 4 shows an example of a rCBF profile across several cortical activation fields. The figure indicates that this cluster analysis rather sharply defines the fields, which would not vary greatly in size and form if they were thresholded at minimum levels from about 8 to $12 \mathrm{ml} / 100 \mathrm{gm} / \mathrm{min}$ change in $\mathrm{rCBF}$.

$R C B F$ image evaluation. The anatomically standardized pictures were analyzed for local field activations occurring in the brain as clusters of voxels having high signal-to-noise ratio (Roland, 1993). The statistical analysis of the cluster detection was described extensively in a recent report (Roland et al., 1993). Briefly, it was as follows. For each subject, subtraction pictures, $\triangle \mathrm{rCBF}$, were made by voxel-by-voxel subtraction of the rCBF picture of the rest from the test picture. Only voxels for which the $\triangle \mathrm{rCBF}$ values could be considered normally distributed were included in the further analysis; the remaining voxels were set to zero. Mean and variance pictures as well as descriptive Student's $t$ pictures were calculated. Voxels with $t$ values of $>2.00$ were considered clustered if they were attached by side, edge, or corner. Based on an analysis of randomly occurring clusters of voxels having $t>2.00$ in test minus test pictures of the same test repeated twice, a distribution of the occurrence of false positives was made, that is, clusters appearing in the brain picture just due to noise. With reference to this distribution it was decided to reject the hypothesis of all clusters of size 10 and above (having more than 10 voxels) belonging to the distribution of false positives. This implies that there will be on the average 1.6 false positive clusters in the three-dimensional picture representing the brain. For the more restricted space of the cortical motor areas as defined in this study (bilateral M1, PMA, and SMA), the average probability of finding one false positive cluster of size 10 and above was 0.045 . The descriptive $t$ image was thresholded by only accepting voxels having $t>2.00$ and occurring in clusters of size 10 and above; all other voxels were set to zero. This

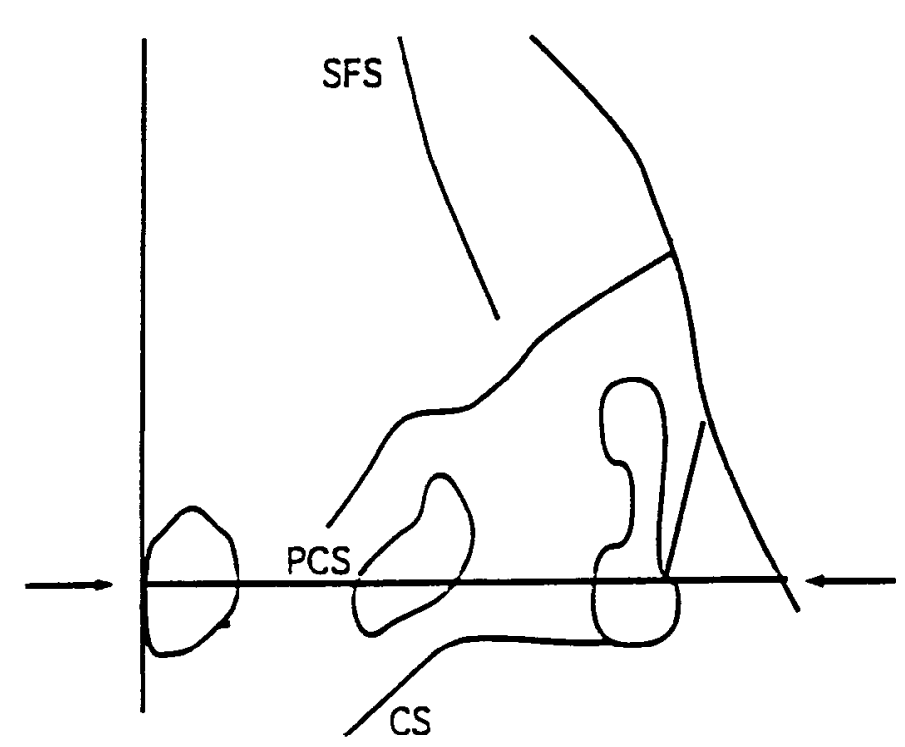

$\mathrm{mi} / 100 \mathrm{~g} / \mathrm{min}$

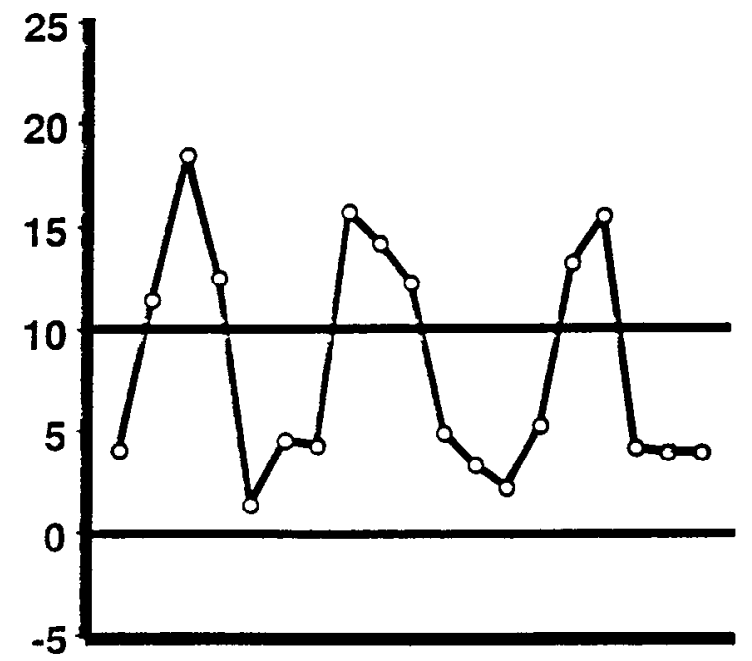

Figure 4. An example of $\mathrm{rCBF}$ profile across cortical activation fields. In the lower panel, a profile of rCBF changes is plotted as they occur along a line drawn across several cortical activation fields (upper panel). This line is arrowed and passes medially to laterally across three separate activation fields, which were defined from the mean subtraction image of final preparation minus rest. The delimitation of activation fields in this study was based on the statistical analysis of the cluster detection. The figure shows that this cluster analysis rather sharply defines the fields.

image is called a cluster image. In this image only clusters of size 10 and above having $t>2.00$ are shown and considered regions of changed rCBF. In Table 1 , the cluster sizes of the activated fields are shown in $\mathrm{mm}^{3}$. One voxel had a volume of $44.03 \mathrm{~mm}^{3}$. The larger the cluster the smaller the probability that it is a false positive. Finally, precise anatomical localization was made of these fields by superimposition of the cluster images onto the mean anatomically standardized MR.

\section{Results}

\section{Behavior}

The performance of each subject was recorded on videotape, and performance accuracy was calculated as the mean distance in centimeters from the center of the targets to the final pointing 
Table 1. Anatomical structures in motor cortices that showed significant $\mathrm{rCBF}$ increases

\begin{tabular}{|c|c|c|c|c|c|c|}
\hline \multirow[b]{2}{*}{ Task } & \multirow[b]{2}{*}{ Anatomical structures } & \multirow{2}{*}{$\begin{array}{l}\triangle \mathrm{CBF} \\
(\mathrm{ml} / 100 \\
\mathrm{gm} / \mathrm{min})\end{array}$} & \multirow{2}{*}{$\begin{array}{l}\text { Volume } \\
\left(\mathrm{mm}^{3}\right)\end{array}$} & \multicolumn{3}{|c|}{$\begin{array}{l}\text { Talairach } \\
\text { coordinates (mm) }\end{array}$} \\
\hline & & & & $\mathrm{X}$ & $\mathrm{Y}$ & $\mathbf{Z}$ \\
\hline \multirow[t]{2}{*}{ Initial preparation } & Precentral gyrus: anterior lip of central sulcus & 12.2 & 484 & 23 & -9 & 54 \\
\hline & Superior frontal gyrus: medial lip of superior frontal sulcus & 14.5 & 704 & 18 & 9 & 58 \\
\hline \multirow[t]{4}{*}{ Final preparation } & Precentral gyrus: anterior lip of central sulcus & 13.7 & 572 & 23 & -8 & 55 \\
\hline & Precentral gyrus: anterior lip of central sulcus to lateral surface & 15.0 & 660 & 38 & -10 & 53 \\
\hline & Superior frontal gyrus: medial lip of superior frontal sulcus & 15.0 & 484 & 20 & 8 & 58 \\
\hline & Superior frontal gyrus: medial surface & 14.3 & 484 & 4 & -14 & 53 \\
\hline \multirow[t]{2}{*}{ Initial reaching } & Precentral gyrus: anterior lip of central sulcus & 13.4 & 660 & 27 & -11 & 54 \\
\hline & Superior frontal gyrus: anterior lip of precentral sulcus & 12.4 & 484 & 18 & -1 & 56 \\
\hline \multirow[t]{3}{*}{ Final reaching } & Precentral gyrus: anterior lip of central sulcus & 11.4 & 792 & 31 & -12 & 54 \\
\hline & Superior frontal gyrus: anterior lip of precentral sulcus & 11.3 & 572 & 18 & 3 & 57 \\
\hline & Precentral gyrus: posterior lip of precentral sulcus & 13.4 & 484 & 31 & -1 & 5 \\
\hline
\end{tabular}

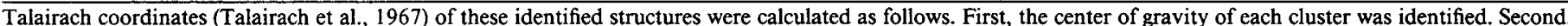

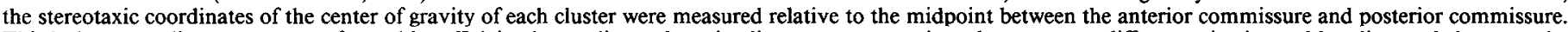

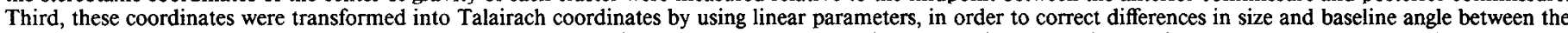

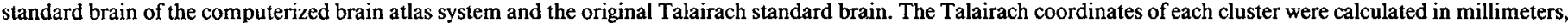

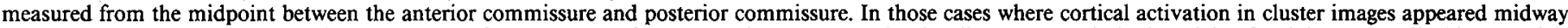

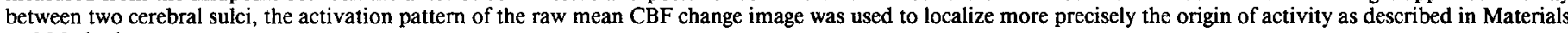
and Methods.

sites ("pointing errors"). After $2.3 \pm 1.5$ trials (mean $\pm \mathrm{SD}$ ) all subjects of the reaching group pointed to the targets in the correct order. The five subjects forming the additional preparation group did so after $2.2 \pm 0.7$ trials. Learning effects were in addition

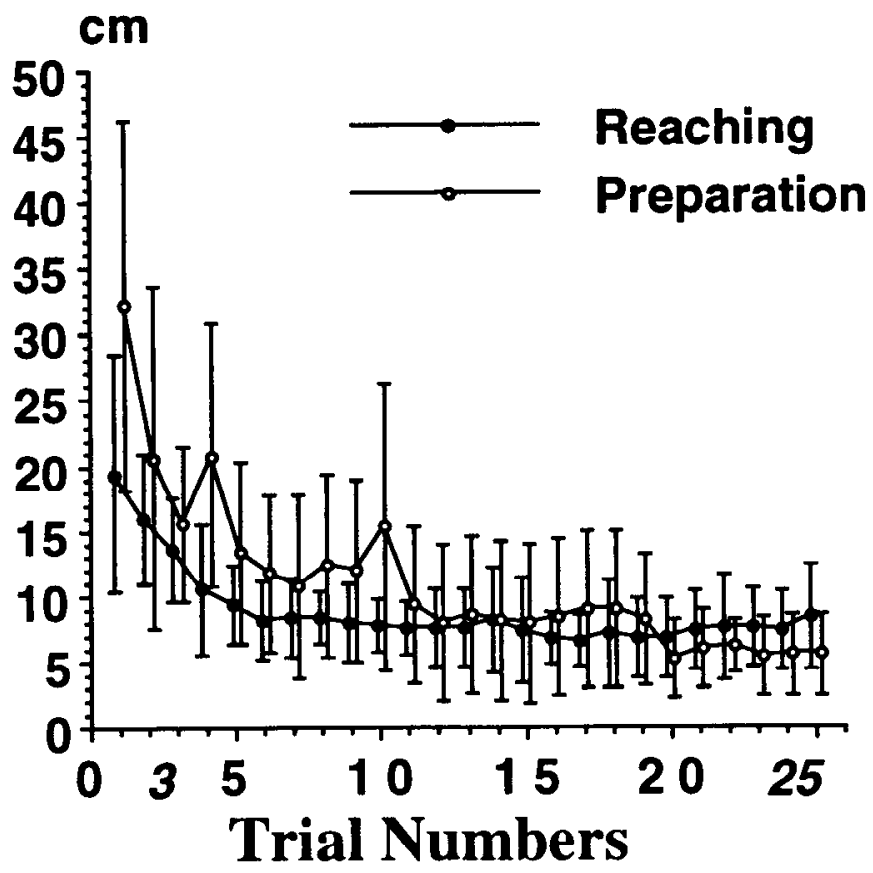

Figure 5. The learning curves for reaching and preparation groups. Each circle and bar indicates the mean and $\mathrm{SE}$, respectively, of pointing errors that were calculated as the mean distance in centimeters from the center of the targets to the pointing sites. Solid circles indicate pointing errors of the reaching group. These were calculated from video recordings made throughout the entire study. Open circles indicate pointing errors of the preparation group, which were calculated from video recordings made of an additional five age-matched subjects performing exactly the same procedure as the preparation group. Learning of this task was judged as the achicvement of smaller pointing crrors. The pointing errors showed a stable state after about the 10 th trial in each group. evaluated as a decrease in the pointing errors. Figure 5 shows the population means of pointing errors for each trial from trial 1 to trial 25 . All subjects satisfactorily learned to perform the task during the course of the study. The pointing errors from the initial learning phase at the 3rd trial (1st PET measurement) to the final learning phase at the 25th trial (2nd PET measurement) showed a statistically significant decrease in both groups (additional preparation group, $p<0.01$; reaching group, $p<$ 0.05 ; paired $t$ test). There was no statistically significant difference in performance between the additional preparation group and the reaching group in the overall performance levels achieved.

EMG recordings from the right forearm during the delay phase of the 3rd trial (initial preparation) and during the delay phase of the 25th trial (final preparation) showed no evidence of muscle activity. Except for the reaching movements of the right arm as well as some eye movements, no other obvious movement of any part of the body was observed on videotape recordings or by dircct observation by the experimenters. In the preparation group, the mean $( \pm S D)$ frequency of eye movements during the three PET measurements (rest, initial preparation, final preparation) was $0.21 \pm 0.10,0.21 \pm 0.09$, and $0.22 \pm 0.10 \mathrm{~Hz}$, respectively. These differences in EOG activity between rest and initial preparation, and between rest and final preparation were not statistically significant ( $t$ test). In the reaching group, the mean $( \pm S D)$ frequency of eye movements during rest, the initial reaching phase at the 3 rd trial (initial reaching), and the final reaching phase at 25 th trial (final reaching) was $0.26 \pm 0.13$, $1.28 \pm 0.29$, and $1.17 \pm 0.22 \mathrm{~Hz}$, respectively. The frequency of eye movements during the rest run was lower than during initial reaching and also lower than during final reaching ( $p<$ 0.01 in both cases, paired $t$ test).

\section{Cerebral activation pattern}

Since there is no gross anatomical way of delimiting the PMA in the human brain, we arbitrarily delimited the PMA posteriorly from the $\mathrm{M} 1$ by a line midway between central sulcus and precentral sulcus on lateral surface of precentral gyrus, and anteriorly from the prefrontal area by a line extending laterally 
from the anterior border of SMA. Superiorly, the limit was the superolateral border of the brain. In the precentral gyrus, the cortex lining the anterior lip of the central sulcus was classified as $\mathrm{M} 1$, and the cortex lining the posterior lip of precentral sulcus was classified as PMA. On the exposed part of the precentral gyrus, the border was drawn at equal distance from the two sulci. The anterior border of SMA was defined by superimposition of the atlas of Talairach et al. (1967) in which the SMA was defined by electrostimulation.

All tasks, initial preparation, final preparation, initial reaching, and final reaching, activated cortical fields in the primary motor area (M1) and in the premotor area (PMA) of the left hemisphere compared with the rest state (Fig. $6 A-D$ ). In addition, the final preparation phase activated the left supplementary motor area (SMA). Quantitative data on changes in mean rCBF for each of these activated fields are summarized in Table 1 .

Fields were classified according to when they were active as follows: type $I$, fields that were active during the preparation phase but were not active during the reaching phase; type II, fields that were active during the reaching phase but were not active during the preparation phase; type $I I I$, fields that were active both during the preparation phase and during the reaching phase. Type II fields were further divided into type IIa, which were consistently active during both reaching phases (initial reaching and final reaching), and type $I I b$, which were active either during initial reaching or during final reaching. The total volumes of these field types in M1 and in PMA are summarized in Figure 7.

The topographic distribution of activated fields in the left motor areas is summarized for the initial and final preparation phases in Figure 8 . The topographic distribution of activated fields in the left motor areas during the initial and reaching phases (trial 25) is shown in Figure 9. In each figure, the preparation and actual reaching fields of activation are indicated for comparison.

Primary motor area. During the initial preparation phase (Fig. 8 ), the activity in M1 was located deep in the anterior lip of the left central sulcus (field 1). The volume of this field (field 1) was $484 \mathrm{~mm}^{3}$. During the initial reaching phase (Fig. 9), a larger field (field $2,660 \mathrm{~mm}^{3}$ ) was activated. These two fields partially overlapped.

During the final preparation phase (Fig. 8), two separate fields were activated within $\mathrm{Ml}$ (fields 5,6 ). One was situated deep in the anterior lip of central sulcus (field 5) partially overlapping the field that was also active during the initial preparation (field 1). The other field (field 6) was situated relatively superficially, close to the surface of the precentral gyrus. The total volume of the fields of activation in $\mathrm{M} 1$ during final preparation (fields 5 , 6) was larger $\left(1232 \mathrm{~mm}^{3}\right)$ than that which appeared in initial preparation (field $1,484 \mathrm{~mm}^{3}$ ).

During the final reaching phase (Fig. 9), the field of activation (field 7) was larger than the activated field during initial reaching (field 2). This field 7 was partially overlapped by field 2 , which was active during the initial reaching. The area of overlap between field 2 and 7 has been designated as ficld 12 in Figurc 10. This specific overlapping field was type IIa (both initial reaching and final reaching). The remainder of field 7 was a type IIb (either initial reaching or final reaching) field, since it was not active during initial reaching. The remainder of field 2 was also a type IIb field, since it was not active during final reaching. Fields active in initial preparation as well as in final preparation (fields $1,5,6$ ) were located in positions adjacent to the type IIa field (Fig. 10).

During the initial learning phases, $54 \%$ of the total volume of activated fields in M1 were type II (reaching only) fields. In contrast, the majority of fields activated during the final learning phase were type I (preparation only) fields (Fig. 7).

In summary, there were four different activation fields in $\mathrm{M} 1$, identified on the basis of their different anatomical location and when they were active. These were fields $1,5,6$, and 12 (Fig. $10)$.

Premotor area and supplementary motor area. Within the PMA, initial preparation activated fields in the medial lip of superior frontal sulcus of the left superior frontal gyrus (Fig. 8, field 3). This activated field disappeared during Initial Reaching (Fig. 9). In contrast, a field of activation in the anterior lip of precentral sulcus of the superior frontal gyrus appeared during the initial reaching (Fig. 9, field 4), although this field had not been active during initial preparation.

During final preparation, the same field in the left superior frontal gyrus (Fig. 8, field 8) was activated as in initial preparation. The same field in the superior frontal gyrus that was active in final reaching (Fig. 9, field 9) was also active in initial reaching (field 4 ). Final reaching also activated a field in the posterior lip of the precentral sulcus (field 10). The areas of overlap between field 3 and 8 and field 4 and 9 have been designated as fields 13 and 14, respectively, in Figure 10. There were no type III (both preparation and reaching) fields in the PMA.

In summary, there were three different activation fields in PMA, identified on the basis of their different anatomical location and when they were active. These were fields 13,14 , and 10.

Within the SMA, there was a ficld of activity in the posterior part that was not present in the initial preparation phase but which appeared during the final preparation phase (Fig. 8, field 11). There was no field of activation in the SMA during reaching.

Effects of visuomotor learning. From Figures 8 and 9, it is apparent that additional fields became active after the learning had taken place. In order to prove that these fields were related to learning (and not to any particular pattern of activity during the rest measurement), we performed the following subtractions: final preparation minus initial preparation and final reaching minus initial reaching. The resulting subtractions revealed fields becoming active during the course of learning. Three such fields were found and are seen in Figure 11. These three fields overlapped the positions of the fields appearing only in final preparation minus rest and final reaching minus rest. The overlapping is shown as the hatched areas in Figure 11. These hatched fields, 15,16 , and 17 , thus appeared by analyzing the material in two independent ways.

\section{Discussion}

In this study, we have demonstrated a topographic distribution of activated fields in the primary motor cortex, the premotor cortex, and the supplementary motor cortex that were related to preparation and execution of movement and to visuomotor learning. The principal findings were (1) that specific fields of activation were identified in M1, PMA, and SMA during the delay phases when there was no actual motor movement and (2) that new fields appeared in M1, PMA, and SMA after learning had taken place. These results give rise to the following three hypotheses: (1) there are specific cortical fields in Ml that are 


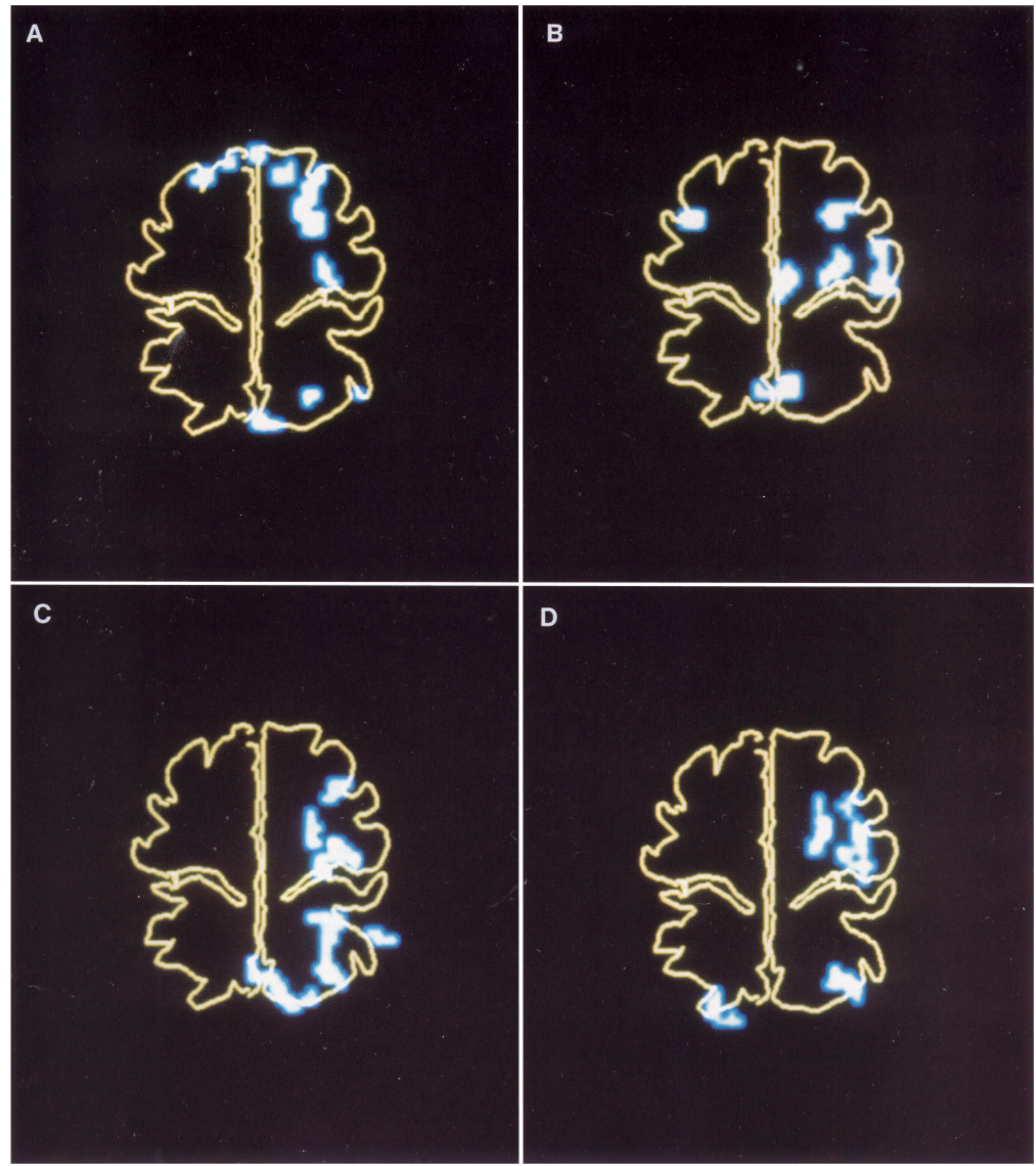

Figure 6. Atlas map of statistically significant changes in rCBF. All four pictures are of the same section through the sensorimotor hand area. The brain surface and central sulci were retrieved from the data base of the CBA program of Bohm et al. (1986). $A$, Initial preparation minus rest. $B$, Final preparation minus rest. $C$, Initial reaching minus rest. $D$, Final reaching minus rest. Right in these images is left in the brain.

not directly involved in muscle contraction but are related to higher-order motor control functions such as the encoding of visuomotor information, (2) specific neurons in M1 are modulated in relation to the learning of new visuomotor information but not related to actual reaching, and (3) in PMA, a new field arose as a consequence of learning and this field was related to actual reaching, indicating that PMA has a direct role in motor control.

In a preliminary report (Decety et al., 1992) in which eight subjects participated, we were unable to find statistically significant changes in the motor areas during initial and final preparation phases. In the present study of the whole group of 10 

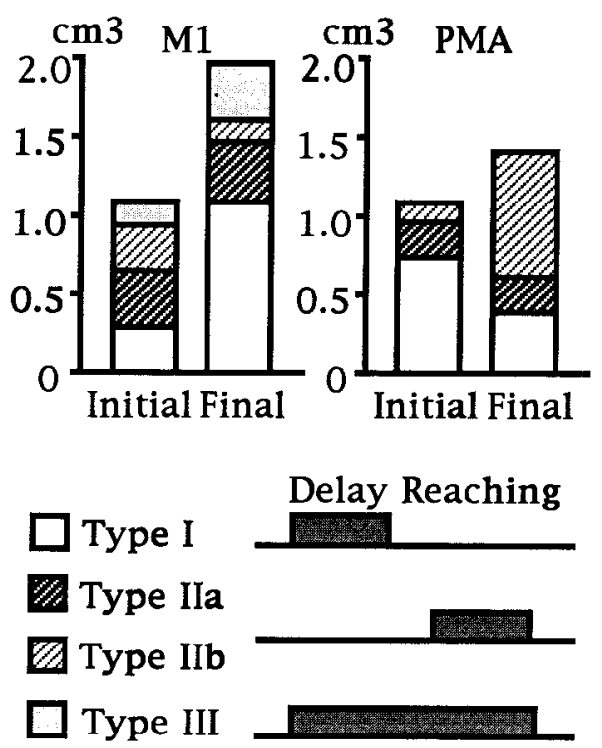

Figure 7. Classification of fields of activation and their volumes. Fields of activation were classified according to when they were active. Type $I$, fields that were active during the preparation phase but were not active during the reaching phase. Type $I I$, fields that were active during the reaching phase but were not active during the preparation phase. Type III, fields that were active both during the preparation phase and the reaching phase. Type II fields were further divided into Type IIa fields consistently active during both reaching movements (initial reaching and final reaching) and Type $I I b$ fields active either during initial reaching or during final reaching. On this figure, Initial indicates the initial learning phase, Final indicates the final learning phase. The volume of activated fields belonging to each activation field type is shown for both initial and final learning phases.

subjects, changes in the motor areas became statistically significant according to our a priori fixed criteria.

\section{Preparatory activity}

Since the visual targets disappeared after each exposure, subjects had to retain this information in the brain over the delay period, during which time no muscle contractions werc observed. Also during the delay period, subjects had to wait for a "POINT" command to initiate their voluntary motor activity. This was not a reaction time task but rather an accuracy task; that is, subjects had to prepare for movement only after hearing the "POINT" command. This means that cortical activation observed only in the motor areas during the $90 \mathrm{sec}$ delay period (type I fields, preparation only) most probably reflects the neuronal implementation of sensorimotor transformations of visual information. It probably does not reflect neuronal activity related to initiation of actual movement ("readiness" to move) since this is usually observed for only a few seconds before muscle contractions commence (Deecke, 1987; Crutcher and Alexander, 1990; Georgopoulos, 1991) and the "POINT" command was given several seconds after the rCBF measurement was finished.

There are several current hypotheses to account for directional coding of reaching movements (Georgopoulos et al., 1983; Soechting and Flanders, 1989; Jeannerod, 1990; Burnod et al., 1992; Kalaska and Crammond, 1992). A consistent feature of these models is that at least three major neural operations are considered necessary in order to establish motor commands. The first one is to generate some form of sensory map that
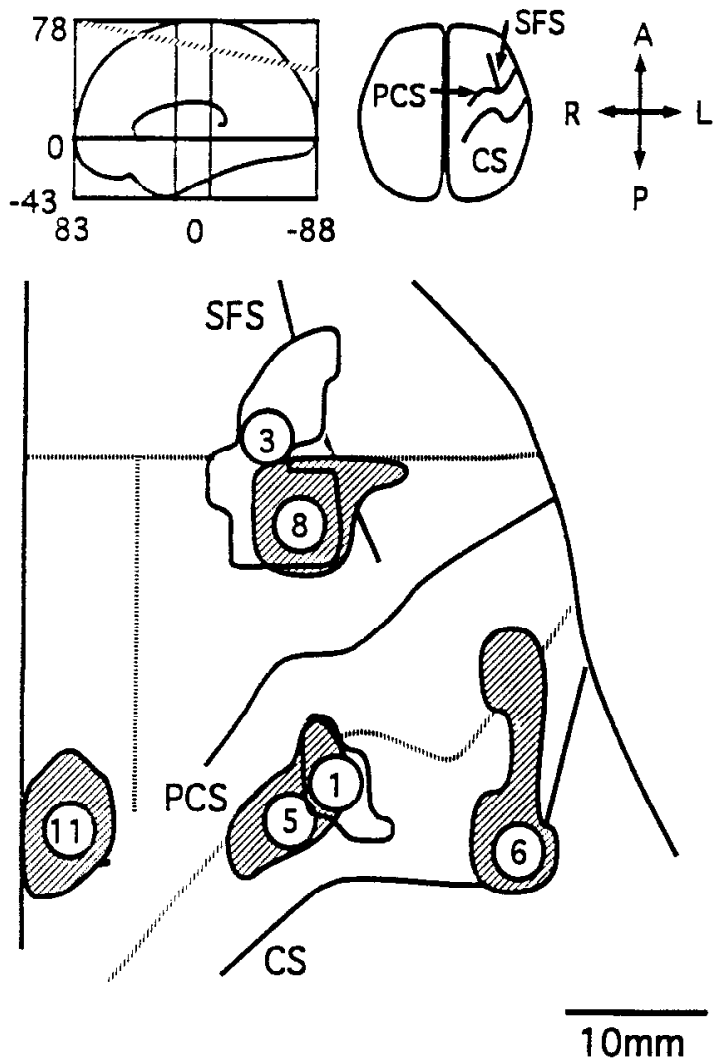

Figure 8. Horizontal section of the brain showing the topographic distribution of activated fields in the left motor areas during the initial and final phases. Top left, Section of the present slice (cross-hatched line) projected onto the frame of Talairach et al. (1967). The contour of the brain and the sulci were drawn from the mean MRI (Fig. 2), and the fields of activation were copied from each PET image. White areas indicate the fields of activation during the initial preparation phase. Shaded areas indicate the fields of activation during the final preparation phase. Broken lines indicate the arbitrary delimitation of the PMA. The PMA was delimited from the prefrontal area by a line extending from the anterior border of SMA. In the precentral gyrus, the anterior lip of the central sulcus was classified as $\mathrm{Ml}$, and the posterior lip of the precentral sulcus was classified as PMA. In this figure, the medial side of the hemisphcre is to the right, and the surface of the hemisphere is to the left. The fields were numbered to identify each field. $A$, anterior; $P$, posterior; $S$, superficial; $M$, medial; $S F S$, superior frontal sulcus; $P C S$, precentral sulcus; $C S$, central sulcus.

encodes target positions as trajectory information in body-centered coordinates. The second is to transform this information into a motor and/or proprioceptive map that encodes trajectory information in arm-centered coordinates. The third operation requires some form of sensory feedback in order to correct the error in attempted reaching movements. Since subjects had their eyes closed throughout the delay and the reaching periods, there was no direct visual feedback during the PET measurements or during the training series.

Previous single-unit studies in monkeys have identified neuronal activity in M1 that is not directly related to peripheral muscle events (Georgopoulos, 1991). It was suggested that thcse neurons may have a function in the encoding of trajectory information. Three cell types have been reported, some active only during a delay period (Godschalk et al., 1981; Weinrich and Wise, 1982; Georgopoulos et al., 1989; Alexander and Crutcher, 1990a; Kalaska and Crammond, 1992), some active only in relation to actual motor movement, while others are 

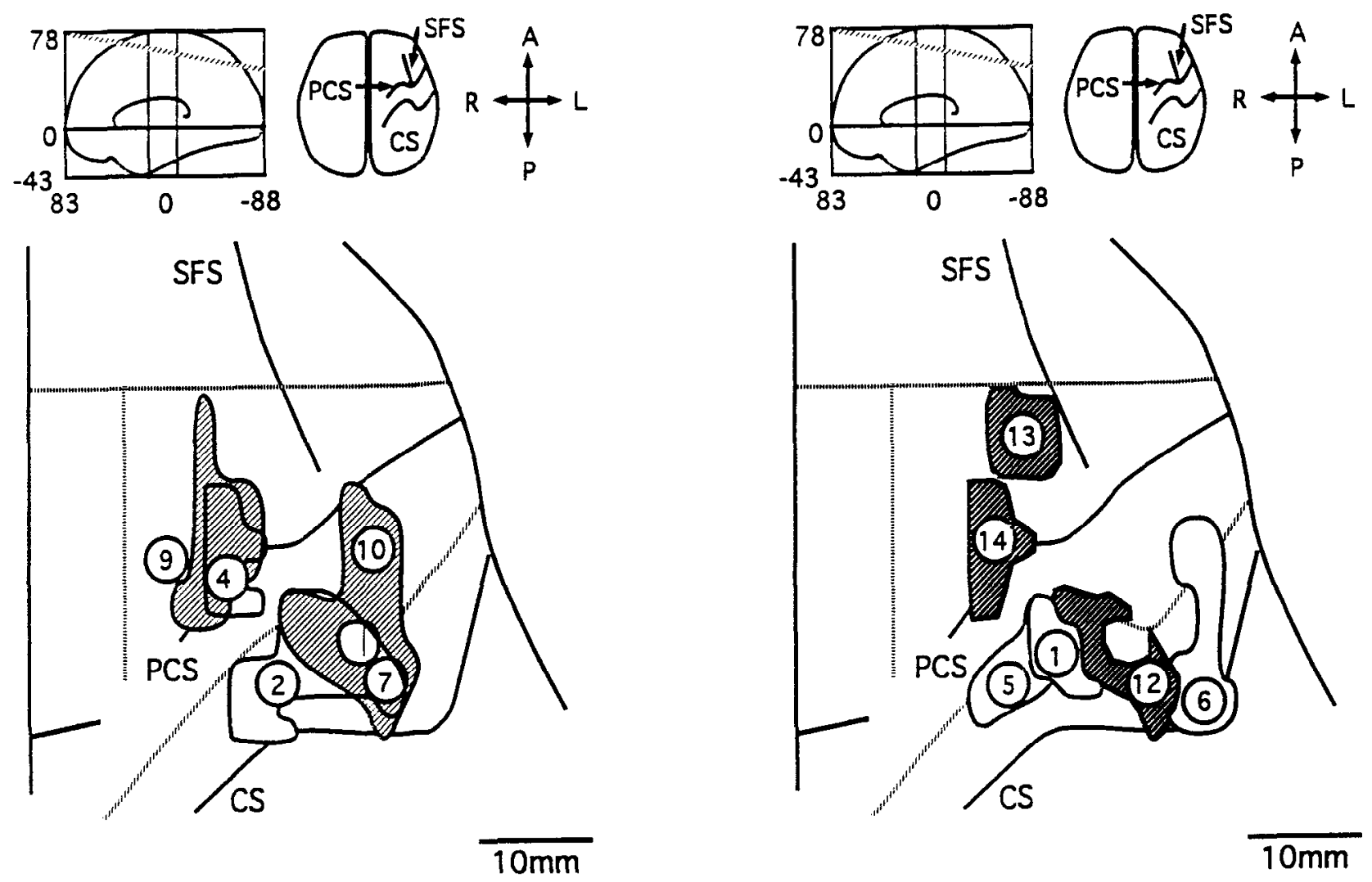

Figure 9. Horizontal section of the brain showing the topographic distribution of activated fields in the left motor areas during the initial and final reaching phases using the same format as Figure 8. White areas indicate the fields of activation during the initial reaching phase. Shaded areas indicate the fields of activation during the final reaching phase.

active both during the delay period and during actual movement (Georgopoulos et al., 1986; Schwartz et al., 1988; Kalaska et al., 1989; Alexander and Crutcher, 1990b; Caminiti et al., 1990). Neuronal activity has also been recorded in PMA during actual motor performance (Weinrich and Wise, 1982; Godschalk et al., 1985; Caminiti et al., 1991) and during a delay period (Godschalk et al., 1981; Weinrich and Wise, 1982; Georgopoulos et al., 1989; Alexander and Crutcher, 1990a; Kalaska and Crammond, 1992), and in the SMA, also during actual performance (Crutcher and Alexander, 1990). Activity of neurons in M1 during the delay phase is said to be less frequently recorded than in the PMA (Kalaska and Crammond, 1992).

In the present study, the rCBF measurement in the preparation group was made during the $90 \mathrm{sec}$ before the start of movement. The onset latencies of neurons described in the above studies that showed directionally tuned activity during a delay period never exceeded a few seconds. However, recently, Wise and Kurata (1989) have shown preparatory activity of neurons in the monkey PMA that persisted for as long as $7.5 \mathrm{sec}$ after an instruction stimulus. That is, the relatively short onset latency times reported in previous monkey studies may have depended upon the specific task procedures, cspecially the time given between the instruction stimulus to the "GO" signal. In our particular study, subjects successfully performed and learned the task, so it might have been possible for them to persist with preparatory activity throughout the $90 \mathrm{sec}$ delay periods. This means that specific fields of activation in the M1, PMA, and SMA that we observed during the delay phases (type I, prepa-

Figure 10. Horizontal section of the brain showing the topographic distribution of the areas of overlap. Format is the same as in Figure 8. The shaded area 12 indicates the location of the type IIa (both initial reaching and final reaching) field in $\mathrm{M} 1$. White areas $(1,5$, and 6 ), which indicate fields active during either the initial preparation or the final preparation, are adjacent to the edge of this type IIa field. The Shaded area 13 indicates area of overlap between field 3 and field 8 (Fig. 8). The shaded area 14 indicates area of overlap between field 4 and field 9 (Fig. 9). There were three different activation fields $(13,14$, and 10) in PMA, identified in this study.

ration only) may well represent the neuronal activity involved in maintaining body-centercd and/or the transformed arm-centered trajectory maps during this time period.

\section{Learning-dependent activity}

This is the first human study that has identified visuomotor learning-dependent activity in regions of the motor cortex. The task used in this study was not intended to be a motor skill learning lask. In fact, the reaching movements themselves were rather easy to perform for these normal subjects (Decety et al., 1992). The subjects were required to learn the visual representation of the targets. They were able to correct (learn) their "body-centered trajectory map" from visual information given during each $5 \mathrm{sec}$ cue period. They also had some opportunity to correct (learn) their trajectory maps (body-centered and/or arm-centered) from sensory feedback during each reaching when they pointed to and touched the screen (a distance between index finger and shoulder, and an angle of the shoulder), although they did not have any direct visual feedback at this time. The learning curves of pointing errors showed that a stable state was achieved in both groups roughly after the 10th trial (Fig. 5). Soechting and Flanders (1989) have suggested that a minimum level of pointing errors will continue, because of errors in the sensorimotor transformation from the visual representation of the tar- 
get locations to the kinematic representation of the arm movement under conditions in which subjects have no visual feedback. The learning effects observed in the learning curves of both groups in our study indicate that the subjects had attained a reasonably accurate visual representation of target locations after this stable state was achieved.

In the present study, fields 15 and 16 in M1 and field 17 in PMA (Fig. 11) showed significant rCBF increases in the subtraction images of the final learning phase minus the initial learning phase. That is, synapses in the parts consistently activated in fields 15,16 , and 17 showed no activity in excess of the rest state during the initial learning phase, but they all significantly increased activity during the course of learning.

Within the $\mathrm{M} 1$, the fields of activation that appeared after learning were type I (preparation only) fields. As discussed above, type I field was not related to muscle contractions. Within the PMA, the activated field which appeared after learning was a type IIb (either initial reaching or final reaching) field. This indicates that PMA became more active in direct motor control and $\mathrm{Ml}$ in addition got new preparatory role. The reaching movements themselves were regarded as identical during initial reaching and during final reaching based on observations of the videotape recordings. Therefore, neurons in the type IIb fields may not relate exclusively to muscle contraction. These findings suggest that neuronal activity in three of the identified activation fields (two type I fields in Ml and a type IIb field in PMA) is associated with the learning of visuospatial information.

Similar learning-dependent changes in neuronal activity have been reported in the PMA and in M1 in monkey studies (Mitz et al., 1991) and also in the prefrontal area (Kubota and Komatsu, 1985; Niki et al., 1990; Watanabe, 1990). Gemba and Sasaki (1988) showed that field potentials over M1 appeared, and increased during learning of a visuomotor task. There have been several EEG studies in humans during motor skill learning (Niemann et al., 1991; Lang et al., 1992). These studies have shown negative DC potentials in mesial frontocentral cortex $(\mathrm{Cz})$ and sensorimotor hand areas of either hemisphere $(\mathrm{C} 3$ and C4) that declined after learning. However, the precise location of changes in these electrophysiological studies remains uncertain. Human PET studies of motor skill learning (Grafton et al., 1992; Seitz and Roland, 1992) have shown increases in rCBF in the contralateral M1, PMA, and SMA during actual execution of the movements. However, in these two studies, no new areas were described in M1, PMA, and SMA due to the effect of learning the skill, in the execution phase of the skill. In the present study, the fields related to visuomotor learning may reflect synaptic modulation that occurs through synaptic plasticity in these motor areas (Asanuma and Keller, 1991).

\section{Activation pattern}

Our study also showed some fields that were active only during the preparation phases (type I), some fields which were active only during the reaching phases (type II), and others which were active during both the preparation phases and the reaching phases (type III). A new finding from the present study is that we were able to scparate the location of thesc different types of cortical activation fields in human motor areas.

Neuronal activity in the activated fields was most probably related to preparation, initiation and execution of movement of the right arm. Another possibility is that some of the activations were associated with eye movements. Eye movements were recorded from the EOG during the reaching phases. How-
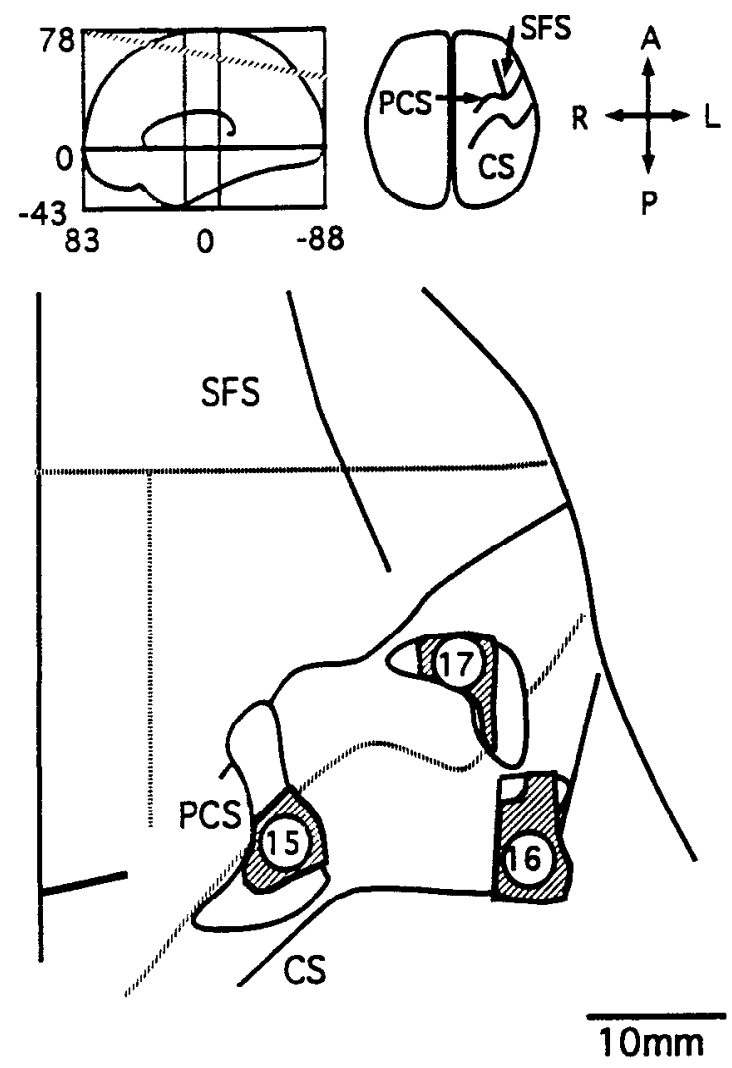

Figure 11. Horizontal section of brain showing areas of increases in mean rCBF appearing after visuomotor learning. The topographic distribution of activated fields is shown in the same format as Figure 8. Fields of activation were estimated from the subtraction images of the final preparation minus the initial preparation and of the final reaching minus the initial reaching (white areas). Within these areas, shaded areas indicate areas which overlapped with fields that were active during the final preparation or the final reaching.

ever, neither M1 nor PMA is considered to have neurons related to eye movements (Weinrich and Wise, 1982; Weinrich et al., 1984; Godschalk et al., 1985; Mauritz and Wise, 1986; Vaadia et al., 1986). Also, the fields of activation in this study were located more superiorly than the location of the frontal eye field.

Primary motor area. The location of the type IIa activation field in M1 that was consistently active during both reaching phases (Fig. 10, field 12) had almost the same stereotaxic coordinates as the fields activated during a visually guided motor tracking task (Grafton et al., 1991), a tactile discrimination of shape (Seitz et al., 1991; Kawashima et al., 1992), and a complicated sequence of finger movements (Seitz and Roland, 1992). That is, neurons in this field may relate exclusively to peripheral motor events (i.e., muscle contractions) in the right hand and arm. This represents the traditional functional role of M1 (Brooks and Thach, 1981; Delong and Georgopoulos, 1981; Evarts, 1981). Our field 12 was located in almost the same place as were the fields of activation in the studies of Seitz et al. (1991), Kawashima et al. (1992) and Grafton et al. (1991), indicating that it was not possible to find any difference in the representation of hand and arm-shoulder movements. Grafton et al. (1991) also reported that they were unable to distinguish between the activated sites in $\mathrm{Ml}$ during voluntary movements of the fingers compared with voluntary movements of the arm. In M1 of the monkey brain, the somatotopic representation of forearm mus- 
cles is broadly distributed (Sato and Tanji, 1989; Schmidt and McIntosh, 1990). Penfield and Boldrey (1937) also described a broad distribution of the somatotopic representation of the forearm in humans. Within $\mathrm{M} 1$, there are bidirectional connections that link movement representations of different digits with each other, and with representations of movements of the wrist, elbow, and shoulder joints (Huntley and Jones, 1991). Thus, it may simply not be possible to separate the somatotopic representation of the arm and the somatotopic representation of the hand in Ml in human subjects by PET techniques.

Fields that showed preparatory activity (fields $1,5,6$ ) were juxtaposed with fields of type IIa (Fig. 10). An interpretation of this topographic distribution may be that some of the activated ficlds in the human M1 are related to control of muscle synergies, but that there also exist, in close association, other fields concerned with higher-order processing of visuomotor information. These different fractional fields would have to be interconnected in some way. In the monkey brain, the specific anatomical distribution of the different kinds of neurons recorded in Ml has been unclear. However, Alexander and Crutcher (1990a) have recently shown that cells that are active only with preparatory activity are located more rostrally to the central sulcus, compared with those that are active only during movement-related activity. This finding indicates that there may be functional separation of these two cell types within M1 in monkeys. The results of the present PET study show that these two types of neurons may also exist in the human primary motor area.

The fields of activation in our study were derived from blood flow measurements integrated over $80 \mathrm{sec}$. This limitation in temporal resolution means that one cannot discuss the hierarchical levels of movement representation based on the onset latency of neuronal activity changes. However, one can argue that fields of activation during the delay period may be involved in the planning of the upcoming reaching movement (Kalaska and Crammond, 1992) and may therefore be at a relatively higher hierarchical level than fields active only during the actual reaching phases.

The proportion of type I (preparation only) activation fields was $26.9 \%$ of the total volume of activated fields during the initial learning phase. As discussed above, type I fields may reflect preparatory activity of neurons in transforming visual information into an arm-centered trajectory map. It is possible that the volume of the activated fields may reflect the numbers of activated synapses (Grafton et al., 1991). This proportion of type I field during initial learning phases is almost the same as the proportion of neurons in the monkey M1 that showed activity changes only during the delay period (Riehle and Requin, 1989; Alexander and Crutcher, 1990a). During the course of the learning, this proportion increased to $55.6 \%$. These findings support the hypothesis that $\mathrm{M} 1$ contains zones that are related to muscle contractions directly, zones that are related to preparatory activity, and zones that change synaptic activity with learning, that is, show plasticity.

Premotor area. The task used in the present study was a delayed reaching task, which was guided both by an internal visual representation and by somatosensory feedback. As discussed in the previous section, the neurons in the type I (preparation only) activation field (field 13), which appeared in the medial lip of superior frontal sulcus of PMA may play a role in the preparation of reaching movements. Neurons in the type II (reaching only) field, which appeared in the anterior lip of pre- central sulcus (field 14), may play a role in the somatosensory guidance (and/or internal visual representational guidance) of reaching movements and of the preparation of movements. This suggestion is consistent with the idea that the PMA is involved in the sensory guidance of movement and in some aspects of motor preparation (Roland et al., 1980b; Wisendanger, 1981; Wise, 1985; Gentilucci and Rizzolatti, 1989; Mitz et al., 1991).

Recent studies in monkeys have demonstrated that the PMA (area 6) is functionally quite heterogeneous (Wise, 1985; Rizzolatti, 1987). The results from the present study are consistent with this view. In contrast with M1, there were no type III (both preparation and reaching) fields in the PMA. The cortex in the medial lip of the superior frontal sulcus (Fig. 8) and in the ipsilatcral surfacc of superior frontal gyrus (Fig. $6 a, b$ ) were activated only during the delay phases. The cortex surrounding the precentral sulcus was activated only during reaching movements (Fig. 9). These observations indicate that (1) fields with different function in PMA appear anatomically segregated, and (2) the cortex surrounding the precentral sulcus (fields 14 and 10) directly relates to movement, that is, an executive control of spinal motor output, in accordance with the anatomical corticospinal projection to the cervical segment of the spinal cord from the PMA (Dum and Strick, 1991).

There were overlapping fields of activation in initial preparation and final preparation in the PMA (field 3 and field 8 ) and in the M1 (field 1 and field 5). There was also partial overlap of fields during initial reaching and final reaching (i.e., type IIa fields), in the PMA (field 4 and field 9), and in M1 (field 2 and field 7). It is possible that the overlapping fields in the PMA (fields 4 and 9) are coactivated with the overlapping ficlds in M1 (fields 2 and 7). Similarly, overlapping fields in the PMA (fields 3 and 8) are coactivated with the overlapping fields in M1 (fields 1 and 5). These coactivations between PMA fields and M1 fields may reflect a topographic relationship for corticocortical connections between M1 and PMA in humans. The learning-dependent fields of activation that were located relatively close to the surface in the precentral gyrus (field 16 and field 17) may also reflect these corticortical connections.

Supplementary motor area. The activation field identified in the SMA appeared only during final preparation (field 11). This field was located in the posterior part of the SMA. The presence of somatotopic organization in the human SMA has been debated. Recently, Fried et al. (1991) demonstrated by electrical stimulation study that the human SMA may be somatotopically organized. According to their results, the specific activation field identified in our study is at a site near the upper extremities representation area.

Roland et al. (1980a) and Fox et al. (1987) have demonstrated increases in $\mathrm{rCBF}$ in the human SMA that occur in the planning of movement, without execution of the movements. Deiber et al. (1991) have also demonstrated this result by removing the effect of motor execution from the analysis by task minus task image subtraction. These findings, together with our results, are consistent with the hypothesis that the SMA plays a specialized role in movements generated from an internal reference (Roland et al., 1980a; Eccles, 1982).

Field 11 did not appear to increase in $\mathrm{CCBF}$ in the subtraction images of final preparation minus the initial preparation. This was probably because it was to some extent already active in initial preparation, although this did not reach statistical significance. 


\section{References}

Alexander GE, Crutcher MD (1990a) Preparation for movement: neural representation of intended direction in three motor areas of the monkey. J Neurophysiol 64:133-150.

Alexander GE, Crutcher MD (1990b) Neural representations of the target (goal) of visually guided arm movements in three motor areas. J Neurophysiol 64:164-178.

Asanuma H, Keller A (1991) Neuronal mechanisms of motor learning in mammals. Neuroreport 2:217-224.

Bergström M, Boethius J, Eriksson L, Greitz T, Widen L (1981) Head fixation device for reproducible position alignment in transmission CT and positron emission tomography. J Comp Assist Tomogr 5:136141.

Berridge MS, Adler LP, Nelson AD, Cassidy EH, Muzic RF, Bednraczyk EM, Miraldi F (1991) Measurement of human cerebral blood flow with (15O)butanol and positron emission tomography. J Cereb Blood Flow Metab 11:707-715.

Bohm C, Greitz T, Blomqvist G, Farde L, Forsgren P, Kinglsey D, Sjögren I, Wiesel F, Wik G (1986) Application of a computerized adjustable brain atlas in positron emission tomography. Acta Radiol 369:449-452.

Brooks VB, Thach WT (1981) Cerebral control of posture and movement. In: Handbook of physiology - the nervous system II (Brooks VB, ed), pp 877-946. Bethesda, MD: American Physiological Society. Burnod Y, Grandguillaume P, Otto I, Ferraina S, Johnson PB, Caminiti $R$ (1992) Visuomotor transformations underlying arm movements toward visual targets: a neural network model of cerebral cortical operations. J Neurosci 12:1435-1453.

Caminiti R, Johnson PB, Urbano A (1990) Making arm movements within different parts of space: dynamic aspects in the primate motor cortex. J Neurosci 10:2039-2058.

Caminiti R, Johnson PB, Galli C, Ferraina S, Burnod Y (1991) Making arm movements within different parts of space: the premotor and motor cortical representation of a coordinate system for reaching to visual targets. J Neurosci 11:1182-1197.

Chiarenza GA, Barzi E, Beretta E, Villa M (1990) The skilled performance positivity after learning a skilled task. Electroencephalogr Clin Neurophysiol 41:172-176.

Crutcher MD, Alexander GE (1990) Movement-related neuronal activity selectively coding either direction of muscle pattern in three motor areas of the monkey. J Neurophysiol 64:151-163.

Dccety J, Kawashima R, Gulyás B, Roland PE (1992) Preparation for reaching: a PET study of the participating structures in the human brain. Neuroreport 3:761-764.

Deecke L (1987) Beritschaftpotentials as an indicator of movement preparation in supplementary motor area and motor cortex. Ciba Found Symp 132:231-250.

Deiber MP, Passingham RE, Colebatch JG, Friston KJ, Nixon PD, Frackowiak RSJ (1991) Cortical areas and the selection of movement: a study with positron emission tomography. Exp Brain Res 84: 393-402.

Delong MR, Georgopoulos AP (1981) Motor functions of the basal ganglia. In: Handbook of physiology - the nervous system II (Brooks VB, ed), pp 1017-1061. Bethesda, MD: American Physiological Society.

Dum RP, Strick PL (1991) The origin of corticospinal projections from the premotor areas in the frontal lobe. J Neurosci 11:667-689.

Eccles JC (1982) The initiation of voluntary movements by the supplementary motor area. Arch Psychiat Nervenkr 231:423-431.

Evarts EV (1981) Motor cortex and voluntary movement. In: Handbook of physiology - the nervous system II (Brooks VB, ed), pp 1083 1120. Bethesda, MD: American Physiological Society.

Fox PT, Pardo JV, Petersen SE, Raichle ME (1987) Supplementary motor and premotor responses to actual and imagined hand movements with positron emission tomography. Soc Neurosci Abstr 13: 1433.

Fox PT, Mintun MA, Reiman FM, Raichle MF (1988) Enhanced detection of focal brain responses using intersubject averaging and change-distribution analysis of subtracted PET images. J Cereb Blood Flow Metab 8:642-653.

Fried I, Katz A, McCarthy G, Sass KJ, Williamson P, Spencer SS, Spencer DD (1991) Functional organization of human supplementary motor cortex studied by electrical stimulation. J Neurosci 11: 3656-3666.
Gelmers HJ (1981) Cortical organization of voluntary motor activity as revealed by measurement of regional cerebral blood flow. J Neurol Sci 52:149-161

Gemba H, Sasaki K (1988) Changes in cortical field potentials associated with learning processes of audio-initiated hand movements in monkeys. Exp Brain Res 70:43-49.

Gentilucci M, Rizzolatti G (1989) Cortical motor control of arm and hand movements. In: Vision in action: the control of grasping (Goodale MA, ed), pp 147-162. Norwood, NJ: Ablex.

Georgopoulos AP (1991) Higher order motor control. Annu Rev Neurosci 14:361-377.

Georgopoulos AP, Caminiti R, Kalaska JF, Massey JT (1983) Spatial coding of movement: hypothesis concerning the coding of movement direction by motor cortical populations. Exp Brain Res [Suppl] 7:327336.

Georgopoulos AP, Schwartz AB, Kettner RE (1986) Neuronal population coding of movement direction. Science 233:1416-1419.

Georgopoulos AP, Crutcher MD, Schwartz AB (1989) Cognitive spatial motor processes. III. Motor cortical prediction of movement direction during an instructed delay period. Exp Brain Res 75:183-194.

Godschalk M, Lemon RN, Nijs HGT, Kuypers HGJM (1981) Behavior of neurons in monkey peri-arcuate and precentral cortex before and during visually guided arm and hand movements. Exp Brain Res 44:113-116.

Godschalk M, Lemon RN, Kuypers HGJM, Steen J (1985) The involvement of monkey premotor cortex neurons in preparation of visually cued arm movements. Behav Brain Res 18:143-157.

Grafton ST, Woods RP, Mazziotta JC, Phelps ME (1991) Somatotopic mapping of the primary motor cortex in man: activation studies with cerebral blood flow and PET. J Neurophysiol 66:735-743.

Grafton ST, Mazziotta JC, Presty S, Friston KJ, Frackowiak RSJ, Phelps ME (1992) Functional anatomy of human procedural learning determined with regional cerebral blood flow and PET. J Neurosci 12 : 2542-2548.

Huntley JW, Jones EG (1991) Relationship of intrinsic connections to forelimb movement representations in monkey motor cortex: a correlative anatomic and physiological study. J Neurophysiol 66:390413.

Jeannerod M (1990) A neurophysiological model for the directional coding of reaching movements. In: Brain and space (Paillard J, ed), pp 49-69. London: Oxford UP.

Kalaska JF, Crammond DJ (1992) Cerebral cortical mechanisms of reaching movements. Science 255:1517-1523

Kalaska JF, Cohen DAD, Hyde ML, Prud'homme M (1989) A comparison of movement direction-related versus load direction-related activity in primate motor cortex, using a two-dimensional reaching task. J Neurosci 9:2080-2102.

Kawashima R, Roland PE, O'Sullivan BT (1992) Functional anatomy of matching and discrimination of shape in man. Soc Neurosci Abstr $18: 1420$

Kawashima R, Yamada K, Kinomura S, Yamaguchi T, Matsui H, Fukuda $H$ (1993) Regional blood flow changes of cortical motor areas and prefrontal areas in humans related to ipsilateral and contralateral hand movement. Brain Res 623:33-40.

Koeppe RA, Holden JE, Ip WR (1985) Performance comparison of parameter estimation techniques for the quantitation of local cerebral blood flow by dynamic positron computed tomography. J Cereb Flow Metab 5:224-234.

Kubota K, Komatsu H (1985) Neuron activities of monkey prefrontal cortex during the learning of visual discrimination tasks with $\mathrm{GO}$ / NO-GO performances. Neurosci Res 3:106-129.

Kuschinsky W, Wahl M (1978) Local chemical and neurogenic regulation of cerebral vascular resistance. Physiol Rev 58:656-689.

Lang W, Beisteiner R, Lindinger $G$, Deecke $L$ (1992) Changes of cortical activity when executing learned motor sequences. Exp Brain Res 89:435-440.

Litton JE, Holte S, Eriksson L (1990) Evaluation of the Karolinska new positron camera system; the Scanditronix PC2048-15B. IEEE Trans Nucl Sci 37:743-748.

Mauritz K-H, Wise SP (1986) Premotor cortex of the rhesus monkey: neuronal activity in anticipation of predictable environmental events. Exp Brain Res 61:229-244.

Mitz AR, Godschalk M, Wise SP (1991) Learning-dependent neuronal 
activity in the premotor cortex: activity during the acquisition of conditional motor associations. J Neurosci 11:1855-1872.

Niemann J, Winker T, Gerling J, Landwehrmeyer B, Jung R (1991) Changes of slow cortical negative DC-potentials during the acquisition of a complex finger motor task. Exp Brain Res 85:417-422.

Niki H, Sugita S, Watanabe M (1990) Modification of the activity of primate frontal neurons during learning of a go/no-go discrimination and its reversal. A progress report. In: Vision, memory and the temporal lobe (Iwai E, Mishkin M, eds), pp 295-304. New York: Elsevier.

Oldfield RC (1971) The assessment and analysis of handedness: the Edinburgh inventory. Neuropsychologia 9:97-113.

Olsen J, Paulson OB, Lassen NA (1971) Regional cerebral blood flow in man determined by the initial slope of the clearance of intraarterially injected ${ }^{133} \mathrm{Xe}$. Stroke 2:519-540.

Penfield W, Boldrey E (1937) Somatic motor and sensory representation in the cerebral cortex of man as studied by electrical stimulation. Brain 60:389-443.

Raichle ME, Grubb RL, Dado MH, Eichling JO, Ter-Pogossian MM (1976) Correlation between regional cerebral blood flow and oxidative metabolism. Arch Neurol 33:523-526.

Riehle A, Requin J (1989) Monkey primary motor and premotor cortex: single-cell activity related to prior information about direction and extent of an intended movement. J Neurophysiol 61:534-549.

Rizzolatti G (1987) Functional organization of inferior area 6. In: Motor areas of the cerebral cortex. Ciba Found Symp 132:171-186.

Roland PE (1984) Organization of motor control by the normal human brain. Hum Neurobiol 2:205-216.

Roland PE (1992) Brain activation. New York: Wiley.

Roland PE, Larsen B (1976) Focal increase of cerebral blood flow during stereognostic testing in man. Arch Neurol 33:551-558.

Roland PE, Larsen B, Lassen NA, Skinhoj E (1980a) Supplementary motor area and other cortical areas in organization of voluntary movements in man. J Neurophysiol 43:118-136.

Roland PE, Skinhoj E, Lassen NA, Larsen B (1980b) Different cortical areas in man in organization of voluntary movements in extrapersonal space. J Neurophysiol 43:137-150.

Roland PE, Eriksson L, Stone-Elander S, Widen L (1987) Does mental activity change the oxidative metabolism of the brain? $\mathrm{J}$ Neurosci 7:2373-2389.

Roland PE, Levins B, Kawashima R, Åkerman S (1993) Analysis of three-dimensional ${ }^{15} \mathrm{O}$-butanol brain activation images. Hum Brain Mapping 1:3-19.

Sato K, Tanji J (1989) Digit-muscle responses evoked from multiple intracortical foci in monkey precentral motor cortex. J Neurophysiol 62:959-970.

Schmidt EM, McIntosh JS (1990) Microstimulation mapping of precentral cortex during trained movements. J Neurophysiol 64:16681682.
Schwartz AB, Kettner RE, Georgopoulos AP (1988) Primate motor cortex and free arm movements to visual targets in three-dimensional space. I. Relations between single cell discharge and direction of movement. J Neurosci 8:2913-2927.

Seitz RJ, Roland PE (1992) Learning of sequential finger movements in man: a combined kinematic and positron emission tomography (PET) study. Eur J Neurosci 4:154-165.

Seitz RJ, Bohm C, Greitz T, Roland PE, Eriksson L, Blomqvist G, Rosenquist G, Nordell B (1990) Accuracy and precision of the computerized brain atlas system (CBA) for localization and quantification in positron emission tomography. J Cereb Blood Flow Metab 10:443457.

Seitz RJ, Roland PE, Bohm C, Greitz T, Stone-Elander S (1991) Somatosensory discrimination of shape: tactile exploration and cerebral activation. Eur J Neurosci 3:481-492.

Soechting JF, Flanders M (1989) Sensorimotor representations for pointing to targets in three-dimensional space. J Neurophysiol 62: 582-594.

Sokoloff L (1981) Localization of functional activity in the central nervous system by measurement of glucose utilization with radioactive deoxyglucose. J Cereb Blood Flow Metab 1:7-36.

Talairach J, Szikla G, Tournoux P, Prossalentis A, Bordas-Ferrer M, Covello L, Iacob M, Memple E (1967) Atlas d'anatomic stéréotaxique du télencéphale. Paris: Masson.

Vaadia E, Benson DA, Hienz RD, Goldstein MH (1986) Unit study of monkcy frontal cortcx: active localization of auditory and of visual stimuli. J Neurophysiol 56:934-952.

Watanabe M (1990) Prefrontal unity activity during associative learning in the monkey. Exp Brain Res 80:296-309.

Waters RS, Samulack DD, Dykes RW, McKinley PA (1990) Topographic organization of baboon primary motor cortex: face, hand, forelimb, and shoulder representation. Somatosens Mot Res 7:485514.

Weinrich M, Wise SP (1982) The premotor cortex of the monkey. J Neurosci 2:1329-1345.

Weinrich M, Wise SP, Mauritz K-Z (1984) A neurophysiological analysis of the premotor cortex of the monkey. Brain 107:385-414.

Wise SP (1985) The primate premotor cortex: past, present and preparatory. Annu Rev Neurosci 8:1-19.

Wise SP, Kurata K (1989) Set-related activity in the premotor cortex of rhesus monkeys: effect of triggering cues and relatively long delay intervals. Somatosens Mot Res 6:455-476.

Wisendanger M (1981) Organization of secondary motor areas of cerebral cortex. In: Handbook of physiology-the nervous system II (Brooks VB, ed), pp 1121-1147. Bethesda, MD: American Physiological Society. 